\title{
Transparency Modeling for Mesh Object Using Ray Tracing
}

\author{
Liliana, Edward Primanata Yoewono, Rolly Intan \\ Informatics department, Faculty of Industrial Technology, Petra Christian University \\ Surabaya, Indonesia \\ lilian@petra.ac.id, edwardyoewono@gmail.com,rintan@petra.ac.id
}

\begin{abstract}
Rendering is a visualization process captures a 3D environment into 2D image. One of various rendering methods is ray tracing. Ray tracing can produce a photorealistic image because it involves several calculations, lighting effects and optic effects. Lighting effects will calculate ambient, diffuse and specular. Optic effects will be gotten from calculation of mirror effect and transparency.

To simulate transparency, we need to consider the material, in this case will represent by its refractive index. To calculate an accurate refraction ray, first the transparent object will be assumed as a solid object. So, the ray will travel inside the object before refract outside the object. Finally, every non-transparent object will keep the ray fall on its surface into an energy map.

Some experiments had done to verify if the caustic effect visualized correctly. The other experiments are conducted to test the influent of refractive index, number of casted ray, light energy and map size toward the caustic's appearance. The more number of casted ray, higher light energy and bigger map size will produce brighter and wider caustic effect. The object's shape will affect where rays refracted. Round shape will gather the refracted ray into a small dense area.
\end{abstract}

Keywords-caustic effect; refraction; ray tracing; transparency; optic effect

\section{INTRODUCTION}

Rendering is a visualization process of $3 \mathrm{D}$ environment into a $2 \mathrm{D}$ image. It is like drawing a $3 \mathrm{D}$ world through a $2 \mathrm{D}$ grid paper [1][2][3][4]. Whatever is seen through each cell will be drawn on the cell. A cell represents a pixel which will be shown on computer screen. Ray tracing is a photorealistic rendering method. It produces color calculation almost same as the real world. The photorealistic quality is gained because ray tracing calculates global illumination, including light effect, mirroring and transparency.

Caustic effect was first introduced in the study entitled Global Illumination using Photon Maps [5], wherein the object used is still a sphere. The next study titled "Modeling of reflection and refraction of light by Shiny Objects and Transparent Objects by Using Ray Tracing" [6] has implemented a caustic effect on the transparent object, but the object that is used is a primitive object. Furthermore, ray tracing research conducted on objects mesh titled "Creating Software to Visualize Transparent Object with Ray Tracing" calculated chromatic caustic effect but still use sphere [7].

\section{METHODS}

There are two kind of different ways to render 3D environment using ray tracing [1][2][3][7]. They are forward ray tracing and backward ray tracing. Forward ray tracing will trace every light emitted by the light source. If the light hit a transparent object, it will be refracted. If the traced ray finally hit the eye through a cell of the grid screen, the color of the hit object will appear on the cell. Actually, not all the ray from light source will hit the eye. No method can predict which ray will hit the eye. So, this way is not effective to render. The more effective way to render is backward ray tracing.

Backward ray tracing will trace back every ray which hit the eye through the cells on the screen. This method is effective for rendering but it only trace one ray from light source which falls on a distinct object. It cannot trace other rays of refracted rays from other object. So, in order to get caustic effect, forward ray tracing should be used.

Equation 1 is used to calculate the ray from light source [1]. Light sources are modeled as spheres with the light position as sphere's centre [1][2][[7][8]. The rays will be casted from the light position toward the sphere's surface, as seen in figure 1.

$$
\begin{aligned}
& P(x, y, z)=(r * \cos (\varphi) * \cos (\theta), r * \cos (\varphi) * \sin (\theta), r \\
& * \sin (\varphi)) \\
& \mathrm{r}=\text { radius } \\
& \theta=\text { azimuth }[0 \ldots 2 \pi] \\
& \varphi=\text { zenith }[-\pi / 2 \ldots \pi / 2]
\end{aligned}
$$

where $\mathrm{r}=$ radius

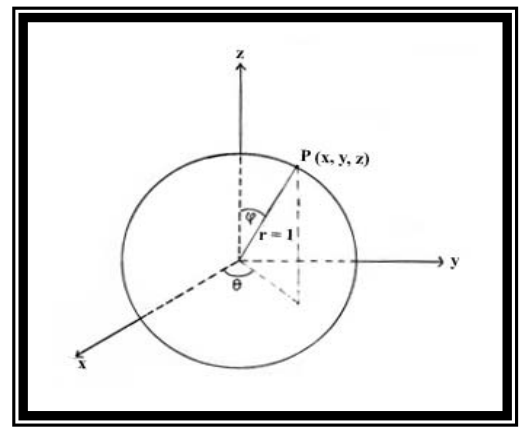

Figure 1. Light source is modeled as a sphere 


\section{A. Energy map}

Energy map also called photon map keeps energy from light source which is refracted from a transparent object [1][3][7][8] toward a non-transparent object. Energy map is a 2D array of point which represents position on non-transparent object's surface[1][7]. If any ray falls on the non-transparent object's surface, the ray's energy will be kept on the 4 nearest points, using bilinear calculation. After keeping all rays energy, the energy accumulation will be divided by the large of the map's size. To spread the energy into its 4 nearest points (p), use equation 2 . The closer the point the more amount energy save on that point. The amount of energy is calculate based on ratio the distant from the neighbor point $\left(\mathrm{d}_{\mathrm{p}}\right)$ with the total distant from fall ray position to its 4 neighbor points(x).

$$
E(p)=\text { energy } *\left(x-d_{p}\right) / 3 x
$$

\section{B. Refraction}

Refraction will happen when a ray travels through two mediums with different refractive index [2][3][7]. If a ray hit a transparent object, it will be refracted, not absorbed. So human's eye will not see its color, but the color of other object behind it. To simulate the refraction, it uses Snell's law as seen in equation $3[1][2][3]$.

$$
\begin{aligned}
& R r=\left(p^{*} n\right)+N^{*}(n-1)^{*} c 1 \\
& c 1=N^{\wedge} p \\
& n=\eta 1 / \eta 2
\end{aligned}
$$

where

$\mathrm{Rr} \quad=$ direction of the refracted ray

$\mathrm{p} \quad=$ direction of the incident ray

$\mathrm{N} \quad=$ normal of the plane

$\eta 1=$ refractive index of material 1

$\eta 2=$ refractive index of material 2

Energy of rays come from lights will be reduced after hit a transparent object. Not only that, the ray also brings the color of the hit object. In this research we add the color of the transparent object accumulatively to the final destination of the refracted ray.

\section{DESIGN AND IMPLEMENTATION}

To get the caustic effect, there are two phases should be done. The first phase is casting rays from light source(s) tracing them through the transparent objects, refracting them toward other objects, if they finally fall on a non-transparent object, keeping their energy into energy map. Energy map is a property of non-transparent object. They are used to keep every ray's energy fall on non-transparent object's surface. These energy maps will yield caustic effect. The flowchart of this phase can be seen in figure 2 .

Phase 2 is rendering process. Basically, it will calculate ambient, diffuse and specular. To add the caustic effect, the calculation will be added by energy kept on energy map. The detail process will be described on flowchart in figure 3 .

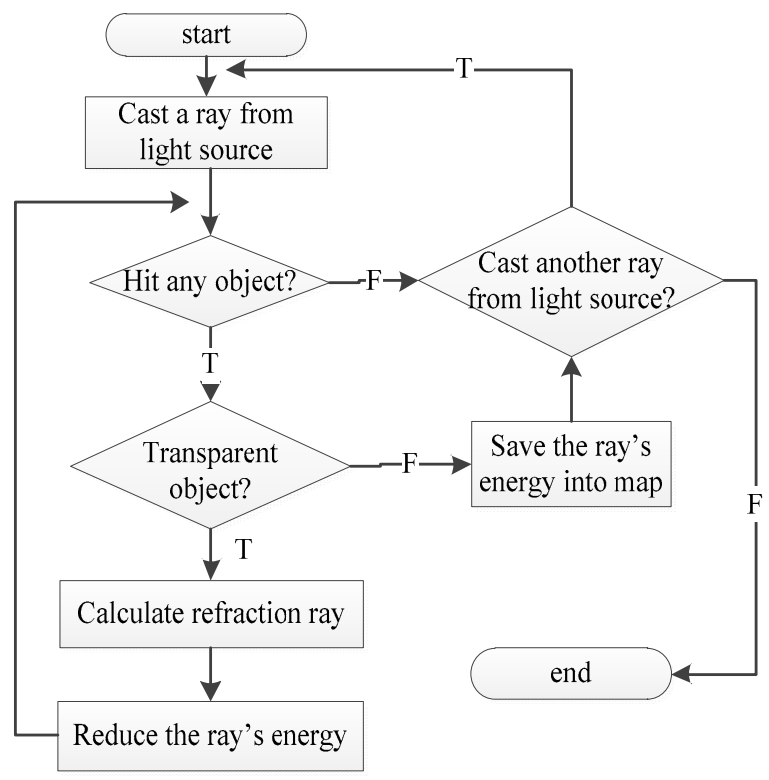

Figure 2. Flowchart of phase 1, keeping energy on energy map
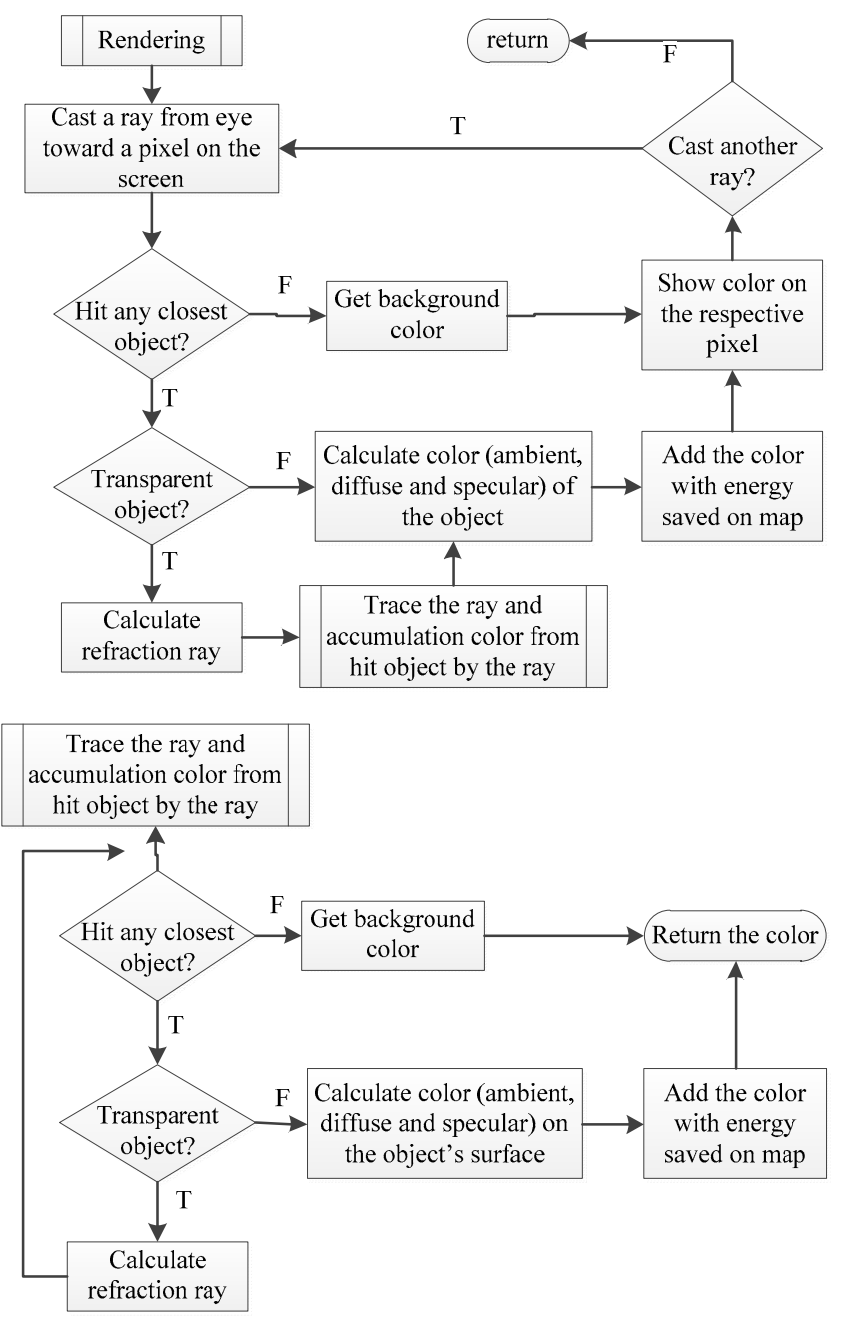

Figure 3. Phase 2, rendering process 
In rendering process, if any ray hit a transparent object, it will be traced until it hit a non-transparent object. The colour calculation of the non-transparent object will be added to the colour of the transparent object.

\section{EXPERIMENT}

Some experiments have done to test this implementation's performance. Aspects that affect the performance are material and light source. We test some different refraction indexes that indicate the thickness of the transparent object. The other experiments test the light's effect with different amount of rays and different energy. Rays that cast from light source are mapped on opaque object's surface. Some experiments run to test caustic effect produced by different size of map.

\section{A. Experiments on different refraction indexes and different kind of object's bottom}

Three kinds of refractive index used in these experiments are 1.3 (ice), 1.9 (flint glass) and 2.4 (diamond) [3]. The objects whose flat, taper and round bottom, are used in these experiments. We used a green teapot, white crystal and pink ball. These experiments are done to know if the application produces refraction modeling correctly. The result of these experiments can be seen in table 1 .

TABLE 1. THE INFLUENCE OF REFRACTION INDEX TOWARD SEVERAL KIND OF OBJECT'S BOTTOM AND SOME DIFFERENT REFRACTION INDEXES

\begin{tabular}{|c|c|c|c|}
\hline $\begin{array}{c}\text { Refractive } \\
\text { Index }\end{array}$ & $\begin{array}{c}\text { Object with flat } \\
\text { bottom }\end{array}$ & $\begin{array}{c}\text { Object with } \\
\text { taper bottom }\end{array}$ & $\begin{array}{c}\text { Object with } \\
\text { round bottom }\end{array}$ \\
\hline 1.3 & & & \\
\hline 1.9 & & & \\
\hline 2.4 & & & \\
\hline & & & \\
\hline
\end{tabular}

Table 1 shows the higher refractive index produces brighter and wider caustic effect on flat and taper bottom objects but different effect on round bottom object.

\section{B. Experiments on different number of ray and different light energy}

On these experiments we cast different number of rays from light source with light energy 35 . The other set of experiments cast 90.000 rays with different light energy. Light energy represents the light intensity. The goal of these experiments is to measure the brightness of caustic effect. The result of brightness level based on number of casted rays can be seen in Table 2 while brightness level based on light energy can be seen in table 3 .

TABLE 2. CAUSTIC EFFECT APPEARANCE BASED ON THE NUMBER OF RAYS

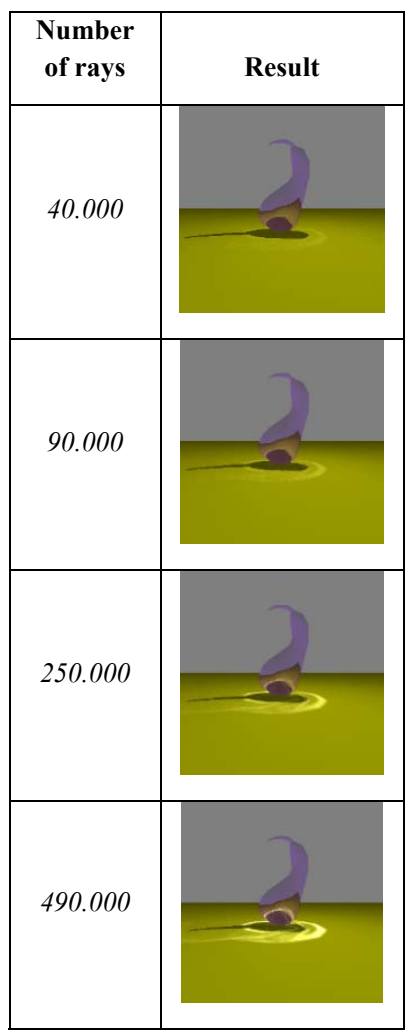

TABLE 3. CAUSTIC EFFECT PRODUCED BY DIFFERENT LIGHT ENERGY

\begin{tabular}{|c|c|}
\hline $\begin{array}{c}\text { Light } \\
\text { energy }\end{array}$ & Result \\
\hline 5 & \\
& \\
\hline 10 & \\
\hline
\end{tabular}




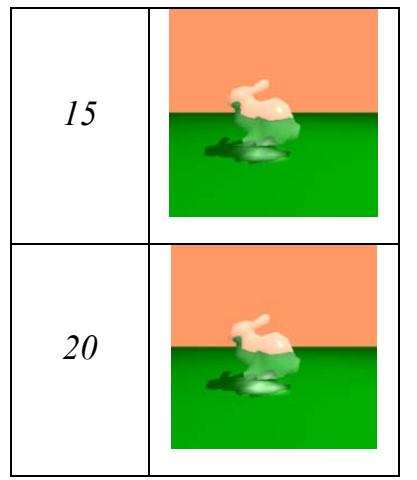

\section{Experiments on different map size}

These experiments had done to examine how the map's size effects the appearance of the caustic effect. Table 4 show the spotted effect if the small size is used. The bigger the map size, the wider the spot area and finally, they will joint with the nearest area. The map size represents how wide the area where the refracted rays fall. The spotted appearance shows us that we predict the caustic area narrower than should be. The right prediction will produce a smooth caustic effect.

TABLE 4. CAUSTIC EFFECT VISUALIZATION BASED ON MAP SIZE

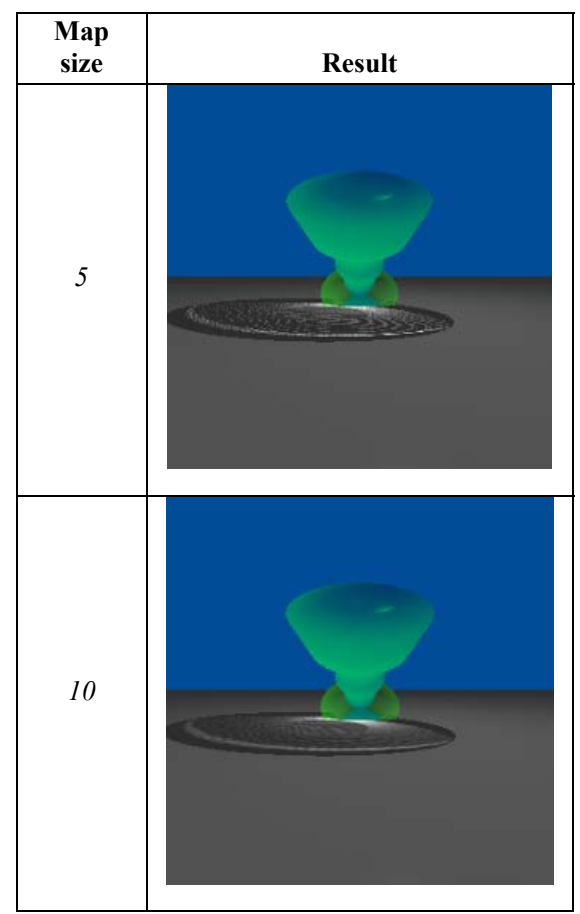

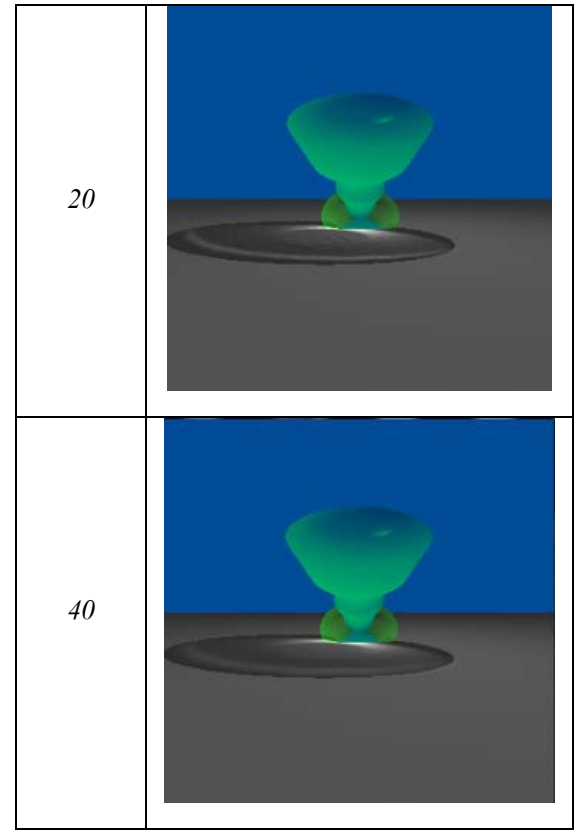

\section{CONCLUSION}

Based on experiments had had done, our proposed method produced caustic effect correctly. Refractive index and shape of object's bottom determine how far the ray refracted from the transparent object. Some external factors influent the caustic effect's appearance as it should be. Number of casted rays and light energy control the brightness of caustic effect. The map size, where the refracted ray kept, will affect the smoothness of caustic effect's appearance.

\section{REFERENCES}

[1] Arvo, J . 1986. Backward Ray Tracing. Apollo Computer, Inc. Chelmsfort, MA

[2] Francis S. Hill,Stephen M. Kelley, "Computer Graphics : using OpenGL", Pearson Prentice Hall, 2007

[3] H.W Jensen, P. Christensen, "High Quality Rendering Using Ray Tracing and Photon Mapping", Siggraph 2007 Course 8, 2007

[4] P. Rademacher, "Ray Tracing: Graphics for the Masses", n.d. Retrieved from : https://www.cs.unc.edu/ rademach/xroads-RT/RTarticle.html

[5] H. Jensen, "Global Illumination using Photon Maps", 1996. Retrieved Jan. 1, 2015 from: http://graphics.ucsd.edu/ henrik/papers/photon_map/

[6] D. Laventhal, "Ray Tracing", 2011. Retrieved from: https://courses.cs.washington.edu/.../ray-tracing

[7] Liliana. "Creating Software to Visualize Transparent Object with Ray Tracing". Jurnal Informatika vol 5 no 1. pp 1-6. Petra Christian University, 2004.

[8] Y. Zhang, Z. Dong and K.-L. Ma, "Real-Time Volume Rendering in Dynamic Lighting Environments Using Precomputed Photon Mapping", IEEE Trans. Visualization and Computer Graphics, vol. 19, no. 8, pp. $1317-1330,2013$ 